\title{
A questão da língua brasileira e o despontar do linguista Gladstone Chaves de Melo
}

Saul Cabral GOMES JÚNIOR ${ }^{1}$

\footnotetext{
${ }^{1}$ Faculdade Fernão Dias (FAFE), muiraquitan.saul@bol.com.br, orcid.org/oo०o-০o०3-
} 2090-451X. 
RESUMO Este trabalho, inserido no âmbito da Historiografia Linguística, visa a relacionar a questão da língua brasileira com o contexto histórico-epistemológico em que se inicia a produção metalinguística de Gladstone Chaves de Melo. A fundamentação teórica tem como base a noção de horizonte de retrospeç̧ão, estabelecida por Auroux (2006), e, sempre que o material de estudo o permite, faz-se uso da noção de formação discursiva, elaborada por Foucault (1969). Comprova-se que Chaves de Melo aderiu ao clima de opinião vigente em seu tempo e se opôs à ideia de "língua brasileira". Conclui-se que Melo dedicou-se a conservar os laços linguísticos entre Brasil e Portugal, porque identificava nesses vínculos a norma exemplar.

ABSTRACT The aim of this work, inserted in the field of Linguistic Historiography, is to relate the Brazilian language issue to the historical-epistemological context in which Gladstone Chaves de Melo initiated his metalinguistic production. The theoretical part of this article is based on retrospective horizon as established by Auroux (2006) and, whenever the material on focus allows, the discursive formation as proposed by Foucault (1969) is also approached. The research comes to the conclusion that Chaves de Melo joined the prevailing climate of opinion in his time and 
he opposed the idea of "Brazilian language". It is the conclusion of this work that Melo was dedicated to preserving the linguistic ties between Brasil and Portugal, because he saw these links as exemplary norm.

PALAVRAS-CHAVE Gladstone Chaves de Melo. Historiografia Linguística. Discurso.

KEYWORDS Gladstone Chaves de Melo. Linguistic Historiography. Discourse. 


\section{Introdução}

Neste estudo, inserido no âmbito da Historiografia Linguística, objetiva-se explicitar a urdidura histórico-epistemológica na qual emerge o linguista Gladstone Chaves de Melo, vinculando-a à profusão de estudos sobre o português do Brasil, a qual assinalou a metalinguagem nacional na primeira metade do século XX.

Ao cerne da fundamentação teórica, integrou-se a noção de horizonte de retrospeç̧ão, estabelecida por Auroux (2006), para quem não se pode analisar a elaboração do conhecimento sem a vincular à temporalidade, à confluência de fatos (histórico-sociais e epistemológicos) em meio aos quais o saber é produzido. A partir dessa noção, demonstra-se a importância de se observarem as ocorrências que extrapolam a esfera da produção metalinguística, constituindo a tessitura social no bojo da qual a metalinguagem foi elaborada.

Empregou-se o método histórico-descritivo, mantendo-se este trabalho na linha de investigação histórico-discursiva, em cuja esfera se estabelece como meta a descrição dos fatos históricos ao longo dos quais ocorre a formação discursiva ${ }^{2}$ de um autor.

\section{Um contexto discursivo, um autor em formação}

\subsection{A bipolarização metalinguística em Portugal}

No final do século XIX, a Filologia portuguesa ramificou-se em duas tendências: a primeira, de caráter prescritivo, concentravase na elaboração de gramáticas e de tratados que contivessem as

\footnotetext{
${ }^{2}$ Termo estabelecido por Foucault (1969), que define formação discursiva como o conjunto de referências nas quais se baseia a configuração de um discurso. A partir dessas referências, que podem ser depreendidas das remissões presentes no discurso do indivíduo, constituemse as concepções e atitudes intrínsecas a um determinado discurso.
} 
diretrizes para a prática da escrita e da fala corretas; a segunda, de cunho investigativo, voltava-se para a substantificação da norma culta ${ }^{3}$ a partir da investigação de textos literários e oficiais, além de se incumbir do estudo histórico do português e de pesquisas sincrônicas que revelassem aspectos da língua falada em Portugal.

Na primeira década do século passado, as duas tendências já estavam solidamente instauradas e, entre si, mantinham uma relação de mútua repelência. Os prescritivistas julgavam demasiadamente liberal a postura dos partidários da investigação, aos quais atribuíam a pecha de abdicar do zelo pela boa linguagem. Os adeptos da Filologia investigativa consideravam ultrapassada a postura dos prescritivistas, aos quais conferiam a qualificação de caturras, apegados a questões linguísticas inférteis e desvinculados do objetivo de descrever efetivamente a língua.

Ao se estabelecer essa bipartição no cerne da Filologia portuguesa, duas figuras despontam, como ícones de cada uma das tendências referidas acima: Cândido de Figueiredo e Leite de Vasconcelos. O primeiro torna-se a personificação do prescritivismo, ao passo que o segundo assume a função de propagador da Filologia investigativa.

Cândido de Figueiredo dedicou-se, com afinco, à Lexicografia. Elaborou glossários e dicionários, nos quais transparece nitidamente sua postura conservadora. Nos verbetes por ele estabelecidos, evidencia-se a concessão de absoluta prioridade à delimitação do que é e do que não é correto. Define Figueiredo (1978, p. 814): "Deparar, v.t. Fazer aparecer. Apresentar inesperadamente: deparou-me o acaso um amigo. V. i. - Tem-se usado com a significação de encontrar alguém ou alguma coisa, topar, mas não é correcto"4.

\footnotetext{
${ }^{3}$ Nota-se que, embora não se deixasse nortear pelo parâmetro prescritivista, a Filologia investigativa assentava-se num fundamento normativo, pois preconizava a instituição de uma norma-padrão baseada na investigação dos textos escritos.

${ }^{4}$ Neste trabalho, as citações contêm, precisamente, a grafia original dos textos transcritos.
} 
Figueiredo adota como parâmetro a linguagem dos clássicos e, sobre ela, erige um modelo ideal de língua, no qual se deveria fundamentar a prática do bem escrever e do bem falar. Camões é um dos cânones nos quais se baseia o lexicógrafo para condenar determinadas manifestações linguísticas de sua época. Expõe Figueiredo (1930, p. 11-12):

Várias vezes me tenho referido ao emprêgo clássico do pronome todo. Da mesma fórma que os Franceses distinguem tout peuple (qualquér povo) e tout le peuple (o povo inteiro), os nossos clássicos distinguiam toda casa (qualquér casa) e toda a casa (a casa inteira). [...] Portanto, Camões, que também escreveu toda minha pena e outras expressões análogas, respeitou a índole da língua e a prática autorizada, ao cantar por toda parte as armas e os barões..., embora tenhamos hoje de tolerar por toda a parte, que infelizmente se generalizou.

No excerto acima, o filólogo vale-se da figura de Luís de Camões - cuja escritaévinculadaà obediência aouso autorizado dalíngua-para fundamentar sua aversão ao emprego generalizado da construção "por toda a parte". Desse modo, o lexicógrafo reprova explicitamente uma determinada manifestação linguística e utiliza uma referência preestabelecida para justificar sua atitude intolerante.

Corroborando-se a bipolarização instaurada no âmago da Filologia lusitana, Leite de Vasconcelos personifica a oposição a Cândido de Figueiredo. Esse autor, segundo Vasconcelos, representava uma corrente obsoleta de filólogos, mantenedores de uma postura que impedia o progresso do estudo filológico autenticamente científicos.

\footnotetext{
${ }_{5}^{5}$ Essa concepção de cientificidade, adotada pelos partidários do investigativismo, relacionase a um "pensamento divergente" que se integrara à Filologia portuguesa, segundo o qual se deveria priorizar a descrição da língua, abdicando-se da postura conservadora dos prescritivistas. Sobre a dialética dos "pensamentos convergente e divergente", inerente
} 
Fez-se notória a contenda acadêmica entre Figueiredo e Vasconcelos, transferindo-se para o plano do debate pessoal a incompatibilidade das duas tendências filológicas. Vasconcelos (1894, p. 1) chegou a criticar formalmente as concepções filológicas de Figueiredo, enfocando a carência de cientificidade que seria intrínseca à produção do prescritivista:

\begin{abstract}
Não estranhei que o sr. Candido de Figueiredo se azedasse com a minha crítica, porque quem, como elle, não trabalha por amor da sciencia, não póde gostar de que o censurem elhe descubrão os erros grosseiros que eu lhe descobri; mas do que me admirei em extremo foi o de o sr. Figueiredo ter a petulancia de responder com má fé litteraria, chocarrices, citações inexactas e falsidades scientificas á argumentação serena e aos factos positivos, ou pelo menos logicamente deduzidos, com que o combati [...].
\end{abstract}

A falta de exatidão e a presença de sofismas - propriedades atribuídas, na citação anterior, ao trabalho filológico de Cândido de Figueiredo - são tópicos integrados ao discurso de Leite de Vasconcelos, que os associa à metalinguagem ${ }^{6}$ do prescritivista português e os dissocia da sua própria elaboração metalinguística. Discursivamente, o cânone lusitano converte a profundidade investigativa no sustentáculo de sua prática científica, destinada à explicitação da importância de se focalizar o uso da língua. Tal procedimento, segundo Vasconcelos (1894, p.4), não estava presente na composição metalinguística de Figueiredo:

\footnotetext{
à produção científica, discorre Kuhn (1992). O autor estabelece a seguinte conceituação: o "pensamento convergente" corresponde a um período em que o processo de produção científica se deixa caracterizar pela continuidade e pela acumulação, ao passo que o "pensamento divergente" é correlato a um período de descontinuidade e ruptura, dentro do qual se concebe um novo 'modelo científico', incomparável e incomensurável em relação ao que o precedeu.

${ }^{6}$ A metalinguagem consiste na utilização da língua para uma reflexão acerca da própria língua. Neste estudo, toma-se metalinguagem na acepção de “episteme voltada para a língua”.
} 
O sr. Figueiredo chama $<<$ tolissimo $>>$ a acceite, e diz que eu <<engoli >> a sua argumentação! Elle tinha começado por condemnar acceite, substituindo-o por acceito. $[\ldots]$

Ora acceite é de uso tão geral, que não só vem nos jornaes ${ }^{7}$, etc., mas philologos competentes, como os srs. Adolpho Coelho e Epiphanio Dias, lhe derão (como mostrei) foros de cidade. E ella vem já noutros diccionarios, por exemplo no Contemporaneo. Por tanto satisfaz a uma das condições essenciaes.

O investigativista português preconiza a focalização do uso da língua, atitude que o induz a se contrapor à reprovação das formulações linguísticas que não se encontram no texto literário clássico. Vasconcelos (1894, p. 5) opõe-se, portanto, à postura reprovativa assumida por Figueiredo, metonímia do prescritivismo lusitano:

[...] assim como ninguem repelle ENTREGUE, ASSENTE, LIVRE, QUITE e ESTREME (que fazem de participios), ninguem deve tambem repellir ACCEITE, visto que é palavra geralmente usada. O não vir ella nos classicos, se é que não vem, não é motivo contra a acceitação da palavra, desde o momento que ella é boa e usada: pois de quantas palavras nos servimos, com que nunca sonhou Vieira nem Bernardes? Os classicos não fazem a lingua.

A partir desse embate explícito, institui-se uma gradativa preponderância da Filologia investigativa. Estabelece-se então, na pesquisa filológica empreendida em Portugal, uma franca propensão a se superar a abordagem puramente prescritiva da língua.

\footnotetext{
7 Note-se que Vasconcelos já menciona os jornais como referência para o uso da língua escrita, anulando a hegemonia do texto literário como parâmetro para a aceitação das formas linguísticas.
} 
Para essa superação, contribuiu, fundamentalmente, Leite de Vasconcelos, autor que atribui à atividade filológica, primordialmente, a função de subsidiar a interpretação dos textos literários clássicos. Declara Vasconcelos (1929, p. 844-845):

[...] com o conhecimento do método filológico, é mais fácil aproveitar [os] primitivos documentos literários da nossa vida política, e lançar neles grande parte da luz de que carecem para a sua interpretação e valorização. [...] como compreender bem sem [a Filologia] o Cancioneiro de Resende, Fernão Lopes, e Gil Vicente, por exemplo?

Na concepção do filólogo lusitano, como se demonstra no fragmento anterior, os documentos literários são o material no qual se deve fundamentar a atividade filológica. A partir da análise desse material, a Filologia desempenharia um papel científico (ao descrever a trajetória de uma língua desde a sua origem) e, ao mesmo tempo, cívico (ao inteirar o público leitor da história política de seu país).

Em consonância com a tendência preponderante na Filologia europeia da segunda metade do século XIX e com a sua visão investigativa da língua, o mestre português confere à variação sincrônica o caráter de objeto de estudo filológico, equiparando-a à variação diacrônica no plano dos elementos a serem estudados pelos pesquisadores da língua.

Vasconcelos imbui-se do interesse pelos fatos linguísticos contemporâneos, especificamente pelos fatos intrínsecosà realidade linguística do ambiente rural, mais propensa à conservação. $O$ filólogo adota, então, a concepção de que a pesquisa filológica deve concentrar-se tanto nas manifestações linguísticas presentes nos textos antigos, quanto nas atuais realizações linguísticas verificáveis nos diferentes falares, visando-se a uma comparação entre as elaborações linguísticas expressas por meio dessas duas modalidades. 
Para o pesquisador Leite de Vasconcelos, registrar os diferentes falares se tornou um objetivo. Propulsionado por essa meta científica, Vasconcelos (1955, p. 18) dedicou-se ao registro de aspectos do dialeto falado na região portuguesa de Barrancos:

Da apócope do $-s$ originaram-se plurais iguais a singulares: xapéu (chapéu), cincu xapéu; casa, cincu casa. E ao mesmo tempo uniformidade de flexões verbais: laba, $2^{\mathrm{a}}$ pessoa do singular, igual à $3^{\mathrm{a}}$; lababa, $2^{\mathrm{a}}$ pessoa do singular, igual à $1^{\mathrm{a}} \mathrm{e}$ à $3^{\mathrm{a}}$.

Ao empreender a viagem a Barrancos, o cânone português consumou seu projeto dialetológico, o qual foi antecedido pela consciência de que a pesquisa in loco era essencial para os novos caminhos que a Filologia portuguesa adotara. Expõe Vasconcelos (1955, p. 12):

[...] conseguiumas páginas à fala de Barrancos, baseado
nuns apontamentos manuscritos que me dera já não
me lembro quem, e, mais que tudo, em informações
orais do Dr. Higino de Sousa, médico oculista, que
exercia clínica em Lisboa, natural de Barrancos, ora
falecido, e que sabia a linguagem popular da sua terra;
mas convinha-me ouvir falar muita gente, comparar
entre si certas expressões, averiguar pronúncias. E
isso apenas o conseguiria indo a Barrancos eu próprio.

Fundamentando-se em princípios novos e numa metodologia específica, Leite de Vasconcelos manteve a variação linguística sob sua lente de pesquisador. O filólogo lusitano tornara-se, também, dialetólogo.

As proposições epistemológicas de Vasconcelos obtiveram uma considerável adesão dos filólogos portugueses, sobrepondose, continuamente, aos preceitos divulgados por Figueiredo (1925, p. 107), que, àquela altura, verificava defeitos no falar dos personagens de Camilo Castelo Branco: 
[...] Camilo, em várias passagens dos seus livros, emprega o si sem significação reflexa.

É certo; como é certo que em todas essas passagens não figura a prosa autêntica de Camilo, mas a das suas personagens, cujo falar, com os seus regionalismos e defeitos, o romancista procurava sempre reproduzir com a maior naturalidade.

Dessa forma, em Portugal, a produção filológica passou a assumir um caráter predominantemente investigativo, fato que repercutiu na Filologia brasileira.

\subsection{Ecos da bipolaridade lusitana na metalinguagem brasileira: um instante epistemológico e a configuração de um dialefilólogo}

A nova perspectiva científica, originária das proposições de Vasconcelos, mostrou-se atrativa para os filólogos brasileiros, especialmente para Manuel Said Ali, que se tornou, na esfera da Filologia nacional, o principal divulgador da ótica investigativa. O filólogo apontou o declínio do prescritivismo e defendeu a instauração de uma visão analítica ao se estudar a língua. Tal visão, segundo Said Ali (1930, p. 5-6), deveria atingir a mutabilidade das expressões linguísticas, conduzindo as perscrutações filológicas ao âmbito da semântica:

Olinguista de hoje investiga os factos sem preoccuparse com a questão do que é ou deixa de ser correcto. Em geral procuro seguir o mesmo rumo [...].

Acima do modo, antigo e exclusivista, de ver as cousas, está a indagação historica. E a investigação da evolução dos phenomenos não se há de limitar ás mudanças de phonemas e formas grammaticaes, mas estende-se ás expressões que com o tempo se foram trocando 
por outras. Entra-se no dominio da psychologia e da semantica.

O autor voltou-se, com muita propriedade, para as diferenças comunicativas que provêm das situações diversas nas quais se insere o falante, no decorrer do convívio social. Desse modo, a postura científica de Said Ali (1930, p. 51) vislumbra a de um sociolinguista, empenhado para que se reconheçam os diferentes registros, ou seja, os usos linguísticos que variam em função da situação na qual se encontra o indivíduo:

Uma cousa é dirigirmo-nos á collectividade, a pessoas desconhecidas, de condições diversas, e que nos ouvem caladas; outra cousa é tratar com alguem de perto, falar e ouvir, e ageitar a cada momento a linguagem em attenção a essa pessoa que está diante de nós, para que fique sempre bem impressionada com as nossas palavras.

$\mathrm{Na}$ elaboração metalinguística de Said Ali, instituiu-se uma contraposição à intolerância que Cândido de Figueiredo destinava às renovações semânticas do português. Após realizar um minucioso estudo sobre as diversas acepções assumidas pelo verbo assistir, Said Ali (1975, p. 183), em cuja produção filológica se estabelecem abordagens semânticas, apresenta a seguinte conclusão:

Sendo tantas e tão várias as acepções de assistir, tornase muitas vezes necessário atender bem ao contexto e à situação para interpretar o verdadeiro sentido.

É possível que essa polissemia se verificasse mais na língua erudita do que no falar do povo, o qual para expressar-se com facilidade e clareza, dispunha de sinônimos de significação definida, aplicáveis aos diversos casos. 
Evidencia-se, no fragmento anterior, o olhar analítico que o autor dirige ao contexto linguístico, explicitando que nele se baseia a depreensão do sentido de uma palavra. Esse procedimento assegura ao filólogo a qualificação de pioneiro dos estudos semânticos no Brasil, designação que o integra, academicamente, à vertente da Filologia investigativa.

Devido à sua visão analítica da constituição do léxico, o filólogo brasileiro atribuía um caráter falho aos trabalhos filológicos de Figueiredo, a quem Said Ali (1975, p. 31) dirige textualmente uma crítica, ao produzir um artigo acerca de uma obra do prescritivista lusitano:

O Problema da Colocação de Pronomes. - Assim se intitula um livro de cerca de 400 páginas, publicado em 1909, em Lisboa, e que o autor, o Sr. Cândido de Figueiredo recomenda como suplemento às gramáticas portuguesas. É título convidativo e toda a obra que trate de semelhante assunto desperta sempre interesse.

$[\ldots]$

Folheando-se o livro do Sr. Cândido de Figueiredo, salta aos olhos a coleção de exemplos com que encheu bom número de páginas; e, como exemplo convence mais do que a simples regra, esta parte dolivrotem o seu lado simpático, ao menos para os que não examinam os textos. O valor desse trabalho colecionador achase, todavia, grandemente diminuído pela falta de tino e paciência para perscrutar devidamente os textos apurados e as condições em que aparecem.

Na passagem acima, embora reconheça o valor quantitativo do exemplário elaborado por Figueiredo, o investigativista brasileiro destaca a falta de tino e paciência do lexicógrafo ao analisar as ocorrências dos pronomes arrolados. O pesquisador estabelece, assim, uma crítica à análise realizada pelo filólogo português, 
opondo-se explicitamente à perscrutação filológica que oblitera as condições em que ocorrem as manifestações linguísticas.

Said Ali contribuiu, fundamentalmente, para que os filólogos brasileiros adquirissem conhecimento da obra de Leite de Vasconcelos, cujas incursões pelo estudo dos fatos linguísticos contemporâneos inspiraram cânones da Filologia brasileira a se voltar às diferentes manifestações espaciais da língua oral. Assim, ao se iniciar o século passado, começou a se desenvolver no Brasil paralelamente à investigação filológica - um outro tipo de estudo da língua: a pesquisa dos falares brasileiros.

O empreendimento da investigação desses falares assinalou a metalinguagem brasileira produzida na primeira metade do século $\mathrm{XX}$, período em que no âmbito nacional se consolidou a pesquisa dialetológica, configurada a partir da produção abundante de obras destinadas ao português do Brasil. Nesse momento peculiar da metalinguagem brasileira, afloram os dialefilólogos, denominação atribuída, neste artigo, aos filólogos empenhados no estudo dos falares. Entre esses pesquisadores, inclui-se Gladstone Chaves de Melo, que se voltou para o processo de constituição do português brasileiro.

O discurso metalinguístico de Melo se assinala, embrionariamente, pela oposição à ideia de "língua brasileira", difundida pelos expoentes do Modernismo brasileiro. Em 1922, ano em que se realiza a Semana de Arte Moderna, vem a lume $O$ dialeto caipira, obra pioneira de Amadeu Amaral, a partir da qual se delineia a investigação dialetológica no Brasil.

Impulsionados pelo empreendimento dialetológico de Amaral, os escritores modernistas assumiram a função de defensores da "língua brasileira", do modo propriamente brasileiro de falar. Essa atitude modernista originou uma cisão na metalinguagem nacional: de um lado, os que aderiram à noção de "língua do Brasil”; de outro, os 
que identificaram nessa noçãouma falácia a ser suprimida. Instaurouse, dessa forma, um embate ideológico, que se imprimiu na produção filológica brasileira, na primeira metade do século passado.

\title{
2. O português do Brasil: dois vieses discursivos, um embate ideológico
}

No início do século $\mathrm{XX}$, o movimento modernista desencadeou uma insurreição contra os padrões lusitanos de expressão literária. Inclusa na busca da identidade nacional, estava a procura pela língua nacional, alheia aos lusitanismos e apta a servir de matéria-prima para uma literatura autenticamente nacional.

No coloquialismo dos românticos, os modernistas encontraram subsídios para adotar uma postura linguística antilusitana. Revelase isso nas seguintes palavras de Mário de Andrade, registradas por Barbadinho Neto (1977, p.3):

\begin{abstract}
A necessidade nova de cultura, se em grande parte produziu apenas, em nossos parnasianos, maior leitura e conseqüente enriquecimento de temática em sua poesia, teve uma conseqüência que me parece fundamental. Levou poetas e prosadores em geral a um... culteranismo novo, o bem falar conforme às regras das gramáticas lusas. Com isso foi abandonada aquela franca tendência pra escrever apenas pondo em estilo gráfico a linguagem falada, com que os românticos estavam caminhando vertiginosamente para a fixação estilística de uma língua nacional.
\end{abstract}

Essa postura antilusitana se evidencia em várias das orientações de Mário ao então poeta-aprendiz Carlos Drummond de Andrade, como se corrobora ao se observar o parecer que o autor destinou ao poema drummondiano "Nota social". Nesse parecer, registrado por Andrade (1988, p. 37), substantifica-se a oposição à subserviência 
estilística dos literatos brasileiros à norma preconizada por cânones lusitanos, como Cândido de Figueiredo, prescritivista a quem alude incisivamente o escritor paulistano:

Foi uma ignomínia a substituição do na estação por à estação [no poema "Nota social"] só porque em Portugal paisinho desimportante pra nós diz assim. Repare que eu digo que Portugal diz assim e não escreve só. Em Portugal tem uma gente corajosa que, em vez de ir assuntar como é que dizia na Roma latina e materna, fez uma gramática pelo que se falava em Portugal mesmo. Mas no Brasil o sr. Carlos Drummond diz "cheguei em casa" "fui na farmácia" "vou no cinema" e quando escreve veste um fraque debruado de galego, telefona pra Lisboa e pergunta pro ilustre Figueiredo: -- Como é que se está dizendo agora no Chiado: é "chega na estação" ou "chega à estação"? E escreve o que o sr. Figueiredo manda.

Nota-se, no fragmento acima, que o autor reivindica uma efetiva aderência entre a língua falada no Brasil e a língua literária utilizada no âmbito nacional. A partir dessa reivindicação, estabelece-se uma insurreição contra os ícones nos quais assentava a tradição gramatical brasileira.

Mário de Andrade personifica a iconoclastia na qual se baseou o movimento modernista. $\mathrm{O}$ senso libertário, de poder escrever em consonância com a língua falada e a cultura peculiares do Brasil, impeliu os adeptos da estética modernista a se insurgirem contra a reprodução literária dos moldes linguísticos portugueses. Manifestase tal atitude insurreta nos trechos coligidos por Barbadinho Neto (1977, p. 2):

Cassiano Ricardo: “Além da corajosa insubmissão artística, o modernismo se batia por uma linguagem já independente dos lusitanismos sintáticos; mais brasileira no modo de falar e escrever." 
Rachel de Queiróz: "Quem não vê que, diante da língua falada, cheia de sangue e de força, que vem direta do peito para a boca, como o fôlego, aquela outra língua em que a gente escreve parece uma múmia enfaixada em comparação com um homem vivo? [...] Aí, muito se tem lutado, desde que neste país se escreve, para libertar a fala literária dos seus panos de rotina.” Guimarães Rosa: "Tudo tinha de destruir-se, para dar espaço ao mundo novo aclássico, por perfeito."

É esse brado modernista que estimula uma geração de filólogos a proclamar o fosso existente entre o português do Brasil e o de Portugal. Dentre esses filólogos, destaca-se Mendonça (1936, p. 42):

É desta maneira que a língua no Brasil, caracterizada por um conjunto de traços particulares, evoluindo na América independente da sua parenta européia, já vai se diferenciando na sua vasta continuidade geográfica. É assim que este cipó das nossas florestas, o mata-pau, alimentado primitivamente com a seiva da arvore, cresce forte e robusto na sua personalidade, para estrangular depois num abraço fatal o seu bemfeitor... A seiva das línguas tambem participa desse espirito destruidor da naturesa.

Destruir para criar formas novas.

Evidencia-se, no excerto acima, o sentido antropofágico do discurso de Mendonça. Numa relação explícita com o projeto de Oswald de Andrade, o filólogo traça uma natureza destrutiva, a partir da qual se criam "formas novas". Mendonça atribui à natureza o ímpeto apresentado por ele e outros filólogos na busca da comprovação de que a língua do Brasil é diferente da língua de Portugal.

Do ponto de vista do autor, a literatura brasileira já havia rompido com o artificialismo da mera reprodução dos padrões lusitanos, para alcançar a compreensão do povo. Ressalta Mendonça (1936, p. 98): 
E quando se vir que a tendência da fala do Brasil é completamente diversa da fala de Portugal, que a civilização afasta cada vez mais os dois paises graças aos neologismos diferentes para as invenções, que a literatura no Brasil já se tornou brasileira, rompendo com um passado artificial para ser compreendida do povo; que as influências de fatores varios transformaram a nossa pronuncia e nosso vocabulário, criando aos poucos outra sintaxe - só existirá uma coisa a fazer: o brasileiro dar bons dias ao português, como faz na fronteira com o uruguaio, o argentino e o paraguaio.

Uma das referências de Mendonça, para defender a ideia de que o português brasileiro é inteiramente distinto do português lusitano, é Silva (1879, p. 77):

[...] conquanto a pronuncia dos Estados Unidos seja diferente da ingleza, seja muito mais agradavel ao estrangeiro, e lhe torne muito mais facil a intelligencia do inglez; comtudo, creio que um escrito norteamericano não é tão diferente de um inglez, como o é de um portuguez um escrito brazileiro, uma obra em dialecto brazileiro, como dizem os Portugueses.

Silva propõe que os escritores portugueses, por serem europeus, são dotados de um espírito conservador, avesso à inovação estilística. Assevera Silva (1879, p. 47):

[...] em geral os Portuguezes só exigem que o escritor use de vocabulos e frases da lingoa; isto é, de vocábulos e frases que se encontrem nos outros escritores portuguezes. Não importa que seo estylo seja obscuro, fraco, duro, affectado; pois nem por isso deixa de ser benemerito. 
Aos brasileiros, o autor confere um caráter ousado, associado ao reconhecimento de que é o povo quem "faz as línguas". Afirma Silva $(1879$, p. 52):

[...] não evitariamos uma frase, só por não se achar autorisada; isto é, usada por algum escritor portuguez, pois para nós uso de uma frase é o emprego d'ella pelo povo, que é quem faz as lingoas, e essa frase não poderia ser rejeitada por ninguem, quando não fosse contraria á grammatica geral.

A postura entusiástica dos defensores da língua brasileira gera uma reação dos filólogos pertencentes à vertente tradicionalista, constituída de pesquisadores cuja formação se calca na Filologia portuguesa. Instaura-se, a partir dessa reação, uma contracorrente, que se dedicaà produção de obras destinadas a dirimir a tese da "língua brasileira", absorvida esteticamente e divulgada entusiasticamente pelos modernistas.

Anteriormente à publicação da referida obra de Mendonça, Antenor Nascentes e João Ribeiro já haviam se posicionado contra a corrente da língua brasileira.

Nascentes (1933, p. 241-242), cuja formação filológica estava firmemente assentada nos preceitos da academia portuguesa, manifestou, de imediato, clara oposição à ideia de que a língua do Brasil se desvinculara do "formoso idioma do velho Portugal" (expressão utilizada por Augusto Magne, ao prefaciar a edição primordial de Introdução ao estudo da língua portuguesa no Brasil, de Serafim da Silva Neto):

[...] a língua do Brasil, em que pese ao orgulho nacional, não passa de um dialeto ultramarino do português e a Europa assim o considera. [...] O próprio Leite de Vasconcelos reconheceu que a denominação de dialeto, dada ao português do Brasil, ia ferir os nossos melindres patrióticos. 
Nascentes (1981, p. 123) ratifica essa posição, naquele contexto, ao declarar que, se a independência literária brasileira está consumada, a independência linguística não está, em virtude da ausência de uma barreira linguística efetiva entre Brasil e Portugal:

Mas, se a independência literária está realizada, a da língua não está.

São muitas as divergências entre o nosso falar e o de Portugal, mas não são de natureza tal que determinem uma barreira lingüística entre os dois países. Buscando comparação em línguas nórdicas, vemos no grupo escandinavo o dinamarquês e o norueguês, parecidíssimos, mas com caracteres próprios que dão a cada um deles a categoria de língua.

O mesmo não se dá conosco.

Ribeiro (1933, p. 263) emite uma opinião que, posteriormente, serviu de base para as reações condenatórias ao texto de Mendonça:

\begin{abstract}
EPILOGO
A - Lingua nacional - é essencialmente a lingua portuguesa, mas enriquecida na America, emancipada, e livre nos seus proprios movimentos.

Com esse intuito, e nesse fundamento, foram escritas as paginas do nosso livro que não inculcam lingua nova, mas revelam os matizes, as variações, e a originalidade do pensamento americano.
\end{abstract}

A opinião de Ribeiro, para quem a língua nacional é a língua portuguesa enriquecida na América, origina uma assertiva exposta no fragmento acima: não existe uma língua nova. Nessa afirmação, fundamentam-se as reflexões metalinguísticas estabelecidas por Serafim da Silva Neto (apud Houaiss, 1960, p. 83-84): 
O que sucede, muitas vezes, é que o português do Brasil manteve um padrão mais conservador do que o de Portugal. [...] Por exemplo, mantivemos "barbante", que só no norte de Portugal é conhecido, enquanto em Lisboa se usa de "fio" ou algo parecido. Isso não nos autoriza a falar em língua nova, embora o português do Brasil tenha suas características próprias. Não vejo, assim, nenhuma vantagem cultural e mesmo política em criar, em adotar um nome - língua brasileira - para uma realidade que não existe.

No discurso de Silva Neto, realçam-se os contornos políticos do racha instituído entre os filólogos nacionalistas e a corrente tradicional de filólogos, dedicados à elaboração de uma abundante metalinguagem, assentada na preconização dos laços linguísticoculturais entre Brasil e Portugal. A partir da produção dessa metalinguagem, conforme expõe Leite (2006), instaura-se efetivamente o purismo lusitanista, voltado para a conservação - e para a manutenção da hegemonia - da norma-padrão vigente no Brasil àquela altura.

A reação a essa tentativa de conservação se substantificou na elaboração metalinguística de autores como Herbert Parentes Fortes, empenhados em desvelar o complexo colonial que seria determinante para a resistência a se admitir a língua brasileira, cuja aceitação contribuiria para a consolidação da autonomia nacional. Nas proposições de Fortes (1981,p.535-536), evidencia-se a concepção da independência linguística como um apogeu da independência política:

Contra os defensores da língua brasileira autônoma existe uma força brutal, que tem o aspecto da inércia física - às vezes, das manhas de um demônio: - o complexo colonial. O segredo de sua força está em ser ignorado como tal e embuçar-se no sentido de mil 
virtudes. [...] É uma associação de ressentimento, um complexo de inferioridade, segundo o qual não se pode pensar de si mesmo qualquer merecimento senão como exigência dele a um defraudador. [...] Sem dúvida alguma: se o destino de nossa língua estivesse condicionado exclusivamente aos elementos dessa "dialética" afetiva, - jamais ganharia a fecundidade da autonomia.

Materializa-se historicamente, dessa maneira, o embate ideológico entre o purismo lusitanista e o purismo nacionalista (sublimado no momento em que o Modernismo empreendeu a busca da identidade nacional). A tal embate, refere-se Cunha (1970, p. 15-16):

[No início do século $\mathrm{XX}]$ os problemas da língua derivaram naturalmente para o conflito de paixões. As duas correntes - a tradicionalista e a nacionalista esquecem-se dos problemas e passam a viver o conflito de velhos e novos preconceitos. De um lado o purismo exagerado, uma concepção fossilizada da língua; de outro, o anelo por uma língua nacional, própria, desvinculada da portuguesa, o que os mais ardentes chegam, ainda hoje, a considerar um imperativo de nossa soberania.

No âmago dessa incompatibilidade ideológica - a partir da qual se institui o antagonismo nacionalistas X lusitanistas - desponta cientificamente o filólogo Gladstone Chaves de Melo. Ao produzir A língua do Brasil, Chaves de Melo assume patente oposição às asserções de Silva e de Mendonça, qualificando-os como pesquisadores excessivamente apaixonados, carentes de objetividade científica:

[...] foi PARANHOS DA SILVA quem por vez primeira tratou do assunto [diferenças entre o português do Brasil e o de Portugal], em 1789, num livrinho 
intitulado O idioma do hodierno Portugal comparado com o do Brasil, por UM BRASILEIRO. Trata-se, porém, de trabalho fraquíssimo, apaixonado, falto de ciência $[\cdots] .^{8}$

Em 1936, RENATO MENDONÇA nos trouxe o seu já citado O Português do Brasil, onde se reúne considerável soma de fatos, infelizmente desperdiçados, porque interpretados com paixão e subjetivismo deformantes. Eis por que o Autor não pôde furtar-se a cair em contradições. (MELO, 1946b, p. 14)

A atitude oposicionista do pesquisador demonstra sua integração à corrente de filólogos lusitanistas, os quais adotaram o objetivo de ratificar a unidade linguístico-cultural entre Brasil e Portugal, propósito intrínseco ao clima de opinião vigente no meio científicoeducacional brasileiro até meados do século XX.

\section{A opinião vigente e a episteme germinal de Gladstone Chaves de Melo}

\subsection{0 clima de opinião da época}

A noção de clima de opinião, formulada por Koerner (1989), remetenos à opinião descrita pelos filósofos gregos, que a denominaram de dóxa. Ao investigá-la, Chauí (2003, p. 252) elabora uma proveitosa conceituação:

[...] a dóxa (opinião) [...] a confiança ou fé que depositamos na sensação e na percepção ou a opinião que formamos a partir das sensações e do que ouvimos dizer. [...] É a opinião acreditada sem verificação; conhecimento que não foi demonstrado nem provado, mas passivamente aceito por nós pelo testemunho de nossos sentidos, por nossos hábitos e também pelos costumes nos quais fomos educados. É uma crença que se conserva enquanto funcionar na prática da vida

\footnotetext{
${ }^{8}$ Esse fragmento da citação é referente a uma nota de rodapé empregada por Melo.
} 
cotidiana ou enquanto uma outra, mais forte, não a contradisser ou a puser em dúvida.

O conceito estabelecido pela autora, no qual se expõe que a opinião é desprovida de verificação, é condensado na definição sintética de Bunge (2002, p. 269): “Opinião: Crença que não foi aferida em relação à verdade assim como à eficiência”.

A opinião corresponderia, desse modo, a uma aquisição arraigada na experiência coletiva. Na concepção platônica, essa aquisição não assegura um legítimo conhecimento, conforme explana Röd (2004, p. 155):

Os conhecimentos extraídos da experiência, segundo Platão, não conduzem a um saber em sentido verdadeiro, mas tão-somente a uma probabilidade, em princípio, hipotética. [...] Um saber autêntico, apoiado na visão das Ideias, é incondicionalmente certo, definitivo e irretocável; as opiniões, dependentes da experiência, ou as suposições, ao contrário, não passam de coisas mais ou menos prováveis.

A substância experiencial da qual se compõe a opinião permite defini-la como uma ideia geral, uma concepção comum, referente a uma compreensão imediata do mundo. A esse gênero de percepção do mundo, não se impõe a sistematicidade do conhecimento bem fundamentado, mencionado na caracterização que Bunge (2002, p. 107) destina, concisamente, ao termo doxástico: "Referese à opinião ('achismo') mais do que ao conhecimento bem fundamentado".

O clima de opinião consiste, portanto, num conjunto de crenças e de valores, a partir do qual se institui uma sedimentação ideológica, em cujo seio se produz a epistéme, o conhecimento sistematizado. Define Chauí (2003, p. 253): 
[...] epistéme (ciência, isto é, saber verdadeiro), palavra da mesma família do verbo epístamai que significa saber, pensar, conhecer, no sentido de algo adquirido e possuído (ter um saber, ter um conhecimento).[...] A epistéme é o conhecimento adquirido por meio dos atos de intuição intelectual ou das várias nóesis.

Tal sedimentação ideológica se constitui um curso-ideológico-domundo, uma realização humana por meio da qual, num determinado contexto, há uma confluência de ideias para um ponto central. Denominando-a de "curso-do-mundo", Hegel (2005, p. 272) disserta sobre essa realização:

O curso-do-mundo tem em seu poder tal momento, que lhe vale como um momento que tanto pode suprassumir como fazer subsistir [...]. O curso-domundo é a consciência desperta, certa de si mesma, que não se deixa atacar por detrás mas faz frente por todos os lados. Com efeito, o curso-do-mundo é tal que tudo é para ele, tudo está diante dele.

$\mathrm{Na}$ primeira metade do século passado, a sedimentação ideológica, em cujo âmbito se produzia a metalinguagem brasileira, assentava numa concepção fundamental: a unidade linguísticocultural entre Brasil e Portugal. Em tal unidade, concentrava-se o clima de opinião vigente, àquela altura, no meio científico-educacional brasileiro.

Essa vigência se encontra ilustrada na dedicatória de Nicolau Firmino, responsável pela adaptação da Gramática Latina de Madvig (1942) aos programas escolares da época: 
Figura 1: Dedicatória de Nicolau Firmino, tradutor da Gramática Latina de Madvig para o português

$$
\begin{aligned}
& \text { Á } \\
& \text { Mocidade Escolar } \\
& \text { ac Sorngal do sbasil, }
\end{aligned}
$$

duas nações irmanadas pelo sangue, enobrecidas pelas mes. mas tradifôes históricas e eternamente unidas pela amizade, pelo pensamento e pela LINGUA PORTUGUESA.

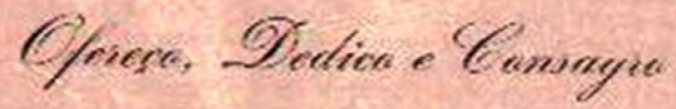

os esforços e sacrificios que fiz para trazer de novo à publi. cidade èste compêndio para o estudo da LINGUA LATINA.

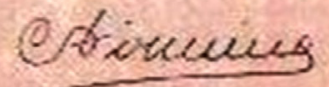

Fonte: Madvig, 1942, p. 01. 
Nesse contexto, preservar os laços linguísticos entre Brasil e Portugal se torna o propósito canônico na Filologia brasileira. Tendo em vista a manutenção desses laços, Marques (1933, p. 7374) condena as inovações estilísticas dos escritores românticos, que teriam preterido os paradigmas da vernaculidade:

[...] a geração romantica, renovada no espirito e na sensibilidade, descurou na escrita o aspecto idiomatico. Desde Alencar, Bernardo Guimarães, Alvares de Azevedo, Varela, Castro Alves, até os seus epigonos, a indiferença para com as normas tradicionais e os paradigmas de vernaculidade introduziu na lingua literaria anomalias e, se assim já se podem chamar, - idiotismos da linguagem usual do país.

Daupiás (1922, p. 44) incumbe-se de corrigir a afirmação equivocada de que estaria se estabelecendo a língua brasileira, diferente da língua falada em Portugal:

Levou-me muito longe a minha primitiva intenção de endireitar uma asserção equivocada. Confio mo releve VExa., não vendo outro-sim nisto tudo senão um sincero desejo de comunhão espiritual mais íntima entre dois países soberanos, que falam a mesma língua, tão opulenta e bela, a língua portuguesa.

Nessa mesma linha de objeção, na qual se reprova a denominação língua brasileira, mantém-se Monteiro (1959, p. 91), apontando a "língua clássica" como uma das maiores obtenções da civilização brasileira:

A unidade da língua é, sem dúvida, fator de unidade nacional. Cultivarmos a língua, pois, mantendo-lhe a disciplina e a pureza, é servirmos a Nacionalidade como lídimos patriotas. Cessem as paixões com que 
se discute o nome da língua nacional. Ela é e deve continuar a ser a língua das boas tradições clássicas, o que representa, sem dúvida, uma das maiores conquistas da nossa civilização.

Leda (1939, p. 149) aprofunda essa concepção de civilização e nela baseia sua contraposição à ideia de língua brasileira, associando tal noção a uma degradação da raça brasileira:

[...] é possivel que a chimera da lingua brasileira continue a entreter o estro dos fantasistas.

[...] Todas as machinações, porém, serão inuteis, porque no Brasil actual, rumo firme para o futuro, não se realizam, felizmente, as condições deploraveis que propiciam as transformações radicaes dos idiomas.

Forte pela unidade o grupo social a que pertencemos e regido ainda, no dominio intellectual, por essa força incontrastavel que é a literatura, não haverá meio de eminenciar a linguistica sertaneja no ápice da nossa cultura, para escarneo da raça e sua relegação ao infimo posto do continente. O interesse collectivo, tanto quanto o pundonor nacional, hão de revocar-nos ao bom senso $[\ldots]$.

Para Augusto Daisson e Arthur Neiva, a ideia de separação linguística entre Brasil e Portugal está arraigada na Filologia portuguesa. Daisson (1925, p. 29) atribui aos filólogos lusitanos a afirmativa de que a língua portuguesa teria sido deturpada pelos falantes brasileiros:

Em Portugal, não ha muito tempo, dizia-se que os brasileiros tinham deturpado, ou, antes, desfigurado o portuguez.

Puro engano. A lingua de Camões permanece intacta. $\mathrm{O}$ que se fez, aqui, foi enriquecel-a com uma variedade enorme de vocabulos, creados pelas exigencias de uma nova vida. As palavras trazidas do mar para a terra, 
pelo açoriano, são tão poucas, que, claramente, não podiam produzir essa tão falada desfiguração.

Neiva (1940, p. 18) deixa mais explícita sua crítica aos filólogos portugueses, especificamente aos lexicógrafos, que estariam obstruindo a instauração de um intercâmbio, no âmbito da metalinguagem, entre os dois países lusófonos:

Contentamo-nos em repetir que o Brasil é riquíssimo, como o fazemos com a lingua que julgamos ser a mais copiosa das existentes. Estaria entre estas, se porventura os lexicografos portuguezes conhecessem muito mais do Brasil e quizessem incorporar a extraordinaria riqueza vocabular que ele originou, nos seus dicionarios. Prefeririamos até nem chamar de brasileirismos; somos a isso forçados porque é assim anotado nos lexicos lusitanos, os principais criadores da separação da lingua dos dois povos, os fazedores de compartimentos estanques, neste particular, entre os dois paizes, quando seria muito mais inteligente $o$ estabelecimento permanente de um sistema de vasos comunicantes.

Contrariando as asserções dos dois autores brasileiros, o filólogo lusitano Agostinho de Campos afirma que a língua falada pelos brasileiros é o português, reivindicando que no Brasil não se dê outro nome à língua portuguesa. Assevera Campos (1948, p. 78):

Portugal, muito longe de ameaçar a independência e integridade do Brasil, continua a enviar-lhe, como há quatro séculos a esta parte, pontualmente e generosamente, do sangue das suas veias e do falar das suas bôcas, os elementos e fôrças de que o Brasil mais precisa para defender contra outros sangues e outras línguas a sua independência e integridade. Não há pois razão, aparente, nem sequer vantagem prática, em que o Brasil dê outro nome, por mais honroso que seja, àquilo que é português. 
Fazendo-se destoantes do clima de opinião, alguns filólogos brasileiros proclamam a existência da língua brasileira. Um deles é Sanches (1940, p. 337-338), em cuja argumentação se amalgamam critérios políticos e linguísticos:

[...] o idioma nacional é, de pleno direito, a LINGUA BRASILEIRA. As lições da linguistica justificam que assim o consideremos. A condição politica lhe assegura e confere essa denominação. É o nosso idioma um dialecto do português. Mas esse dialecto é a linguagem de uma nação soberana na vida internacional. É a nossa "lingua comum". É a nossa "lingua escripta". É a lingua que todos fallamos. É a lingua que todos escrevemos, com excepção apenas dos litteratos que usam o dialecto dos classicos portugueses.

Orientado pelo mesmo propósito discursivo, Marroquim (1934, p. 12-13) focaliza a produção dos escritores modernistas, cujos textos estariam retratando a língua autenticamente nacional:

Felizmente já estão surgindo escritores brasileiros que perderam o medo ao tabú da gramatica "portuguesa" $\mathrm{e}$ estão escrevendo seus livros no português do Brasil, com os modismos sintaticos peculiares ao nosso falar. $[\ldots]$

Mario de Andrade marcha corajosamente na vanguarda do movimento. "Macunaima", alem do espirito de brasilidade de que está impregnado, é tipicamente brasileiro tambem na linguagem.

"Todos cantam sua terra", um dos "Dois ensaios", de Jorge de Lima, está escrito em brasileiro e nem por isso o seu trabalho perdeu qualquer cousa em agudeza e brilho.

Para se opor à noção de "língua brasileira", Chaves de Melo principia sua elaboração metalinguística, iniciada na primeira metade do século passado e enraizada no clima de opinião vigente nessa época. 


\subsection{As trilhas de um linguista-educador e a oposição à ideia de língua brasileira}

Nascido em Campanha (MG), a 12 de junho de 1917, Gladstone Chaves de Melo transferiu-se para Belo Horizonte, onde iniciou o curso de Direito, concluído na Faculdade Nacional de Filosofia da Universidade do Brasil ${ }^{9}$, localizada no Rio de Janeiro (capital da República, naquela época), para onde o autor se mudou, após ficar órfão de pai.

Durante sua adolescência, ainda em sua terra natal, conhece Augusto Magne, então um jovem estudante jesuíta, que, vindo da França, iria se tornar um dos expoentes da Filologia produzida no Brasil. A partir de 1930, estabelecem-se sólidos laços de amizade entre o seminarista e o adolescente, que se deixa fascinar pelos ensinamentos do jovem religioso, em cuja formação sobressai o apego ao estudo das línguas e da cultura humanística.

Em 1941, atendendo-se a uma indicação do Padre Magne, é integrado ao corpo docente da Faculdade Nacional, como assistente da cátedra de Língua Portuguesa, na qual atuava Sousa da Silveira. Nesse ano, consolida-se seu convívio com alguns dos cânones da Filologia brasileira e consuma-se sua vocação para a atividade acadêmica.

Iniciou sua carreira docente no ensino secundário (atual Ensino Médio), mas foi no magistério acadêmico que encontrou um meio de conciliar suas duas paixões: o ensino e a pesquisa. Em meio a uma intensa atividade docente, dedicou-se, com igual intensidade, à produção científica.

No limiar de sua elaboração metalinguística, incursionou pela Dialetologia, ao produzir A língua do Brasil, obra vinda a lume em 1946. Mas foi na pesquisa filológica que o autor avultou. Ao analisar os estudos de português realizados no Brasil, Câmara Jr. (2004, ${ }^{9}$ Atualmente, Universidade Federal do Rio de Janeiro (UFRJ). 
p. 246) cita o notável desempenho de Melo ao efetivar a edição crítica de Iracema:

Do ponto de vista especificamente brasileiro [...] tem maior significação a aplicação da boa técnica filológica aos textos da literatura brasileira, cujas edições no passado vimos muito deixarem a desejar. [...] Gladstone Chaves de Melo, ligado profissionalmente a Sousa da Silveira e ao Padre Magne, fez uma edição crítica de Iracema de José de Alencar, com um estudo complementar sobre a posição de Alencar na questão da língua literária nacional.

Como se alude no fragmento acima, a prática filológica de Melo está indissoluvelmente ligada aos ensinamentos de Sousa da Silveira e de Augusto Magne. As remissões a esses dois autores se materializam, predominantemente, nos trabalhos que o filólogo dedicou à Crítica Textual. Nessa área de pesquisa, a vocação científica de Melo aflorou fulgidamente.

Ao romance Iracema, ele dedicou duas edições críticas, nos anos de 1948 e 1965: na primeira, referida anteriormente, inseriu uma introdução, notas e um apêndice no qual expõe a tese de que Alencar se utilizou da língua portuguesa para construir um estilo brasileiro; por meio da segunda, concedeu uma contribuição acadêmica às comemorações pelo centenário da edição do romance de José de Alencar. A essas edições, juntam-se os estudos críticos que o pesquisador destinou ao romance alencariano Senhora, aos poemas de Alphonsus de Guimaraens e a textos de Rui Barbosa, empreendimentos filológicos agregados pelo propósito de se harmonizarem procedimentos da Ecdótica e da Estilística.

$\mathrm{Na}$ atividade filológica, reuniu os dois campos de sua atuação acadêmica: não só exercitou continuamente a Filologia, como também concentrou nessa área de investigação sua prática de ensino, 
empenhando-se na divulgação dos métodos de pesquisa filológica, principalmente daqueles concernentes à Crítica Textual.

Além do ofício acadêmico, exerceu outras atividades profissionais. Como jornalista, atuou em diversos órgãos, entre os quais se incluem Jornal do Brasil, Correio da Manhã e O Estado de S. Paulo. Na área diplomática, assumiu a função de Adido Cultural da Embaixada do Brasil em Lisboa, por duas vezes: primeiramente, no período de 1962 a 1964; numa fase posterior, após ter sido designado para o Conselho Federal de Cultura, de 1972 a 1974. No campo da política, ocupou dois cargos: em 1950, na legenda da União Democrática Nacional (UDN), foi eleito para integrar a Câmara dos Vereadores do Distrito Federal, permanecendo na função até 1960, em virtude de sua reeleição; em 1960, filiado ao Partido Democrata Cristão (PDC), foi eleito deputado constituinte do Estado da Guanabara.

Embora tenha se dedicado a variadas atividades profissionais, exerceu prioritariamente o magistério acadêmico. Lecionou Língua Portuguesa, inicialmente, na Faculdade Nacional de Filosofia e, posteriormente, na PUC-RJ. Aplicou-se pioneiramente, no Brasil, ao estudo da Estilística, disciplina que lecionou na Universidade Federal Fluminense (UFF), participando da implantação do Mestrado em Letras nessa instituição. Após a Universidade do Brasil tornar-se UFRJ, em 1965, passou a conciliar seus encargos docentes nas três universidades.

O empreendimento educacional de Melo comporta uma bifurcação: além de ter praticado intensamente a docência, o autor dirigiu reflexões a ela. Tais reflexões se incorporam à sua produção metalinguística, conferindo uma peculiaridade a essa obra: a frequente afluência entre perscrutações linguísticas e considerações pedagógicas.

Essas ponderações se fazem presentes, principalmente, em seu ensaio inaugural, A atual decadência da língua literária, texto publicado em1946. Nessaprodução, ofilólogolevantaváriasquestõesreferentes 
ao ensino de Português, dentre as quais se destaca a adoção dos “textos para corrigir", material pedagógico a partir do qual os alunos iriam se habituar a identificar os erros de linguagem. A esse material, Chaves de Melo dirige críticas:

Refiro-me aos "textos para corrigir", moderno processo de aprendizagem (?) da língua. [...] o método em si me parece condenável, porquanto não será por meio de um processo negativo que se há-de aprender a escrever. Depois de ler, estudar, examinar, bisbilhotar mil frases erradas, quais os bons modelos que terá na consciência e no subconsciente um cidadão? (MELO, 1946a, p. 18)

Uma versão ampliada do ensaio em questão foi integrada, como capítulo final, à obra A língua do Brasil, publicada no mesmo ano. Por meio dessa integração, imprime-se um traço pedagógico na referida produção dialetológica, na qual Chaves de Melo opõe-se à ideia de "língua brasileira".

Para construir sua argumentação, o filólogo utiliza como fundamento a recorrência à racionalidade, alicerce no qual assenta a proposição de que a unidade cultural ${ }^{10}$ entre Brasil e Portugal gera a unidade linguística entre os dois países. Atente-se ao seguinte trecho:

[...] na maioria dos casos, é verdadeira a equação: unidade de cultura, unidade de língua. [...]

Aplicando ao caso brasileiro estas considerações: a nossa cultura é européia, é portuguêsa. [...]

A unidade de cultura provoca e sustenta a unidade de língua.

\footnotetext{
${ }^{10}$ A unidade cultural defendida por Melo tem suas raízes no pensamento de Franca (1941, p. 37), autor que institui uma relação entre a consciência dessa unidade e a própria coesão na qual se fundamenta uma nação: “[...] o patrimônio de uma cultura não funda uma nação sem a consciência comum desta unidade cultural. Religião, ciências e artes, línguas, costumes e instituições constituem um fato objetivo, uma herança transmitida pelos maiores".
} 
Eis um raciocínio claro, sereno e objetivo, raciocínio compossível com um patriotismo sadio e bem avisado. (MELO, 1946b, p. 29-30)

Ao preconizar a recorrência à racionalidade, o autor estabelece como prioridade a instauração de um espírito objetivista, à luz do qual seria suprimido um argumento utilizado pelos divulgadores da língua brasileira: Portugal, um país de pequena extensão territorial, não poderia impor sua língua ao Brasil, cuja dimensão territorial é imensa. Chaves de Melo refuta esse argumento, recorrendo, para tanto, ao caso da expansão do latim:

Infelizmente, um argumento que aparece amiúde na dialética dos que defendem a nossa

independência lingüística é este: como pode um país tão pequeno como Portugal, de seis milhões de habitantes, ditar sua língua ao Brasil, êste colosso territorial, sete vêzes mais populoso que o pigmeu da Europa?

$[\ldots]$

Façamos êsse mesmo raciocínio manco para o caso do Latim.

Como poderia uma região tão pequena como o Lácio impor sua língua a quase todo o mundo conhecido naquela época, fazendo desaparecer ante o Latim línguas da importância do Etrusco, por exemplo? [...] É sério o argumento?

Necessário se faz, acima de tudo, espírito científico, espírito objetivista. (MELO, 1946b, p. 27)

A partir da vinculação à racionalidade, na qual se arraiga a instituição de uma visão objetivista, organiza-se o discurso metalinguístico do filólogo. Ao dissertar sobre o espírito científico, proveniente da adoção de uma postura racional, Chaves de Melo ressalta a importância de se manter fiel ao fato: 
O espírito científico exige um esfôrço moral: a isenção, a docilidade ao fato, a obediência à realidade, atitude essa que, em certos casos, nos é custosa. Quantas vêzes uma pesquisa superficial, uma primeira impressão nos levou a arquitetar uma teoria nova e colorida, mas o exame atento e profundo nos convence mais tarde da inconsistência da nossa primeira sistematização! E, neste caso, nem sempre nos é fácil desapegarmo-nos daquele filho prematuro! (MELO, 1946b, p. 70)

Do suporte concedido pelos fatos, o filólogo destitui a tese de que existe uma língua brasileira. Segundo a visão epistemológica de Melo, essa tese não possui a segurança conferida pelos fatos, constituindose de afirmações generalizantes e imprecisas.

\section{Considerações finais}

A formação de Gladstone Chaves de Melo, solidamente assentada na Filologia lusitana, foi decisiva para que ele se dedicasse a conservar os laços linguístico-culturais entre Brasil e Portugal. Ao se dedicar à demonstração dos vínculos existentes entre o português brasileiro e o português lusitano, Melo identifica nesses vínculos a norma exemplar, o patrimônio linguístico em torno do qual brasileiros e portugueses permanecem unidos.

Quando se une discursivamente à vertente tradicionalista, constituída de filólogos que procuravam corroborar a unidade linguística entre Brasil e Portugal, o autor ultrapassa a elaboração metalinguística e pratica a defesa de uma convicção ideológica. Ao se empenhar nessa defesa, Melo estabelece uma tessitura epistemológica na qual prescrever excede preconizar um modelo linguístico, para adquirir sentido de defender uma cultura exemplar. 


\section{Referências}

AMARAL, A. O dialeto caipira. São Paulo: Casa Editora “O Livro”, 1920.

ANDRADE, C. D. A lição do amigo: cartas de Mário de Andrade a Carlos Drummond de Andrade. 2. ed. Rio de Janeiro: Record, 1988.

AUROUX, S. Les modes d'historicisation. In: Histoire, Epistémologie, Langage, t. XXVIII, f. 1, 2006.

BARBADINHO NETO, R. Sobre a norma literária do modernismo. Rio de Janeiro: Ao Livro Técnico, 1977.

BUNGE, M. Dicionário de filosofia. Trad. de Gita K. Guinsburg. São Paulo: Perspectiva, 2002.

CÂMARA JR., J. M. Os estudos de português no Brasil. In: UCHÔA, Carlos Eduardo Falcão (Org.). Dispersos de J. Mattoso Câmara Jr.. Rio de Janeiro: Lucerna, 2004. p. 197-232.

CAMPOS, A. Futuro da língua portuguesa no Brasil. Rio de Janeiro: Edições Dois Mundos, 1948.

CHAUÍ, M. Introdução à história da filosofia: dos pré-socráticos a Aristóteles. 2 ed. São Paulo: Companhia das Letras, 2003.

CUNHA, C. Língua portuguesa e realidade brasileira. 2. ed. Rio de Janeiro: Tempo Brasileiro, 1970.

DAISSON, A. À margem de alguns brasileirismos. Porto Alegre: Livraria do Globo, 1925.

DAUPIÁS, J. G. O dialecto capiau. Rio de Janeiro: Empresas de Publicações Modernas, 1922.

FIGUEIREDO, C. Combates sem sangue: em favor da língua portuguesa. Lisboa: Livraria Clássica, 1925. 
FIGUEIREDO, C. Linguagem de Camões: nas suas relações com a linguagem de hoje. 2. ed. Lisboa: Livraria Clássica, 1930.

FIGUEIREDO, C. Dicionário da língua portuguesa (Volume I - A a G). 15. ed. Lisboa: Livraria Bertrand, 1978.

FORTES, H. P. É preciso situar-se a questão da nossa língua. In: PINTO, Edith Pimentel (Org.). O português do Brasil: textos críticos e teóricos (Volume II 1920/1945). Rio de Janeiro / São Paulo: LTC / EDUSP, 1981. p. 535-538.

FOUCAULT, M. L'archéologie du savoir. Paris: Gallimard, 1969.

FRANCA, L. A crise do mundo moderno. Rio de Janeiro: José Olympio, 1941.

HEGEL, G. W. F. Fenomenologia do espirito. Trad. de Paulo Meneses, com a colaboração de Karl-Heinz Efken e José Nogueira Machado. 3 ed. Petrópolis (RJ) / Bragança Paulista (SP): Vozes / Editora Universitária São Francisco, 2005.

HOUAISS, A. Sugestões para uma política da língua. Rio de Janeiro: Instituto Nacional do Livro, 1960.

KOERNER, K. Practicing linguistic historiography: selected essays. Amsterdam / Philadelphia: John Benjamins, 1989.

KUHN, T. S. The essential tension: selected studies in scientific tradition and change. Chicago / London: University of Chicago Press, 1992.

LEDA, J. A chimera da língua brasileira. Manaus: Imprensa Pública, 1939.

LEITE, M. Q. Metalinguagem e discurso: a configuração do purismo brasileiro. 2. ed. São Paulo: Humanitas, 2006.

MADVIG, I. N. Gramática latina. Trad. de Epifânio Dias / Acomodação aos programas modernos por Nicolau Firmino. Lisboa / Rio de Janeiro / São Paulo: Acadêmica de D. Felipa / Livraria H. Antunes / Livraria Teixeira, 1942.

MARQUES, X. Cultura da língua nacional. Bahia: Escola de Aprendizes Artífices, 1933. 
MARROQUIM, M. A língua do Nordeste. São Paulo: Editora Nacional, 1934.

MELO, G. C. A atual decadência da língua literária. Rio de Janeiro: Imprensa Nacional, 1946a.

MELO, G. C. A língua do Brasil. Rio de Janeiro: Agir, 1946b.

MENDONÇA, R. O português do Brasil. Rio de Janeiro: Civilização Brasileira, 1936.

MONTEIRO, C. Fundamentos clássicos do português do Brasil. Coleção "Silva Ramos”. Rio de Janeiro: Oficinas Gráficas do Colégio Pedro II, 1959.

NASCENTES, A. O idioma nacional (Volume IV). 2. ed. Rio de Janeiro: Livraria Machado / Livraria Alves, 1933.

NASCENTES, A. Independência literária e unidade da língua. In: PINTO, Edith Pimentel (Org.). O português do Brasil: textos críticos e teóricos (Volume II 1920/1945). Rio de Janeiro / São Paulo: LTC / EDUSP, 1981. p. 123-124.

NEIVA, A. Estudos da língua nacional. São Paulo / Rio de Janeiro / Recife / Porto Alegre: Editora Nacional, 1940.

RIBEIRO, J. A língua nacional. 2. ed. São Paulo: Editora Nacional, 1933.

RÖD, W. O caminho da filosofia. Trad. de Ivo Martinazzo. Brasília: Editora da UNB, 2004 .

SAID ALI, M. Meios de expressão e alterações semanticas. Rio de Janeiro: Francisco Alves, 1930.

SAID ALI, M. Investigações filológicas. Rio de Janeiro / Brasília: Grifo / Instituto Nacional do Livro, 1975.

SANCHES, E. Língua brasileira. São Paulo / Rio de Janeiro / Recife / Porto Alegre: Editora Nacional, 1940. 
SILVA, P. O idioma do hodierno Portugal comparado com o do Brazil: por um Brazileiro. Rio de Janeiro: Tipografia de Lourenço Winter, 1879.

VASCONCELOS, J. L. O gralho depennado: réplica às "caturrices" philologicas do Sr. Candido de Figueiredo. 3. ed. Porto: Magalhães \& Moniz Editores, 1894.

VASCONCELOS, J. L. Opúsculos IV (Filologia - Parte II). Coimbra: Universidade de Coimbra, 1929.

VASCONCELOS, J. L. Filologia barranquenha: apontamentos para o seu estudo. Lisboa: Imprensa Nacional, 1955.

\section{Como citar}

GOMES JÚNIOR, Saul Cabral. A questão da língua brasileira e o despontar do linguista Gladstone Chaves de Melo. Revista da Abralin, v. 18, n. 1, p. 01-41, 2019.

Recebido em 16/10/2019 e aceito em 20/11/2019 